\title{
ERA UMA VEZ: A POETICIDADE NA CONSTRUÇÃO DE MENINA NINA: DUAS RAZÕES PARA NÃO CHORAR
}

\author{
Andreia dos Santos Oliveira ${ }^{1}$ \\ Cyntia Graziella Guizelim Simões Girotto²
}

Resumo: 0 artigo em pauta analisa a obra Menina Nina: duas razões para não chorar, de Ziraldo. De cunho autobiográfico, 0 autor utiliza toda a poeticidade permitida nas construções de textos verbais e não verbais para retratar elementos importantes: relação vó/neta e a morte inesperada de um ente querido. Para atingir o objetivo proposto, recorreu-se à análise das duas linguagens que compõem a narrativa: a escrita e a visual. Constatamos que a obra de qualidade estético-literária não somente possibilita que leitores de diferentes idades se identifiquem com a protagonista na perda de um ente querido, como amplia seu conhecimento do mundo e de si mesmo. Ademais uma vivência literária cria afetamentos, contribuindo para humanizar leitores, bem como fomenta novos interesses e desejos pelo ato de ler a produção estéticoliterária materializada nos livros.

Palavras-chave: Literatura infantil. Poeticidade narrativa. Linguagem verbal e não verbal.

${ }^{1}$ Doutoranda em Educação pela Universidade Estadual Paulista Júlio de Mesquita Filho, Câmpus de Marília. Professora de Língua Portuguesa e Literatura do Instituto Federal de Rondônia, campus Porto Velho, Zona Norte. E-mail: andreia.oliveira@ifro.edu.br.

2 Doutora em Educação. Professora da Universidade Estadual Paulista Júlio de Mesquita Filho, CCâmpus de Marília. E-mail: cyntiaunespmarilia@gmail.com. 


\section{ONCE UPON A TIME: POETICITY IN THE CONSTRUCTION OF MENINA NINA: TWO REASONS NOT TO CRY}

Abstract: The article in question analyzes the Ziraldo's work Menina Nina: two reasons not to cry. In an autobiographical way, the author uses all the poeticity allowed in the constructions of verbal and nonverbal texts to portray important elements: grandma/granddaughter relationship and the unexpected death of a loved one. To reach the proposed goal, we used the analysis of the two languages that make up the narrative: writing and visual. We found that the work of aesthetic-literary quality not only enables readers of different ages to identify with the protagonist in the loss of a loved one, but also increases their knowledge of the world and of themselves. In addition, a literary experience creates affection, contributing to humanize readers, as well as foments new interests and desires by the act of reading the aesthetic-literary production materialized in the books.

Keywords: Children's literature. Narrative poeticity. Verbal and non-verbal language.

\section{ERA UNA VEZ: LA POETICIDAD EN LA CONSTRUCCIÓN DE LA NIÑA NINA: DOS RAZONES PARA NO LLORAR}

Resumen: El artículo en pauta analiza la obra La Niña Nina: dos razones para no llorar, de Ziraldo. El autor utiliza toda la poeticidad permitida en las construcciones de textos verbales y no verbales para retratar elementos importantes: relación abuela/neta y la muerte inesperada de un ser querido. Para alcanzar el objetivo propuesto, se utilizó el análisis de los dos lenguajes que componen la narrativa: la escritura y la visual. Se constató que la obra de calidad estético-literaria no sólo posibilita que lectores de diferentes edades se identifiquen con la protagonista en la pérdida de un ser querido, como amplía su conocimiento del mundo y de sí mismo. Además, una vivencia literaria crea afectos, contribuyendo a humanizar lectores, así como fomenta nuevos intereses y deseos por el acto de leer la producción estético-literaria materializada en los libros.

Palabras clave: Literatura infantil. Poeticidad narrativa. Lengua verbal y no verbal. 
Introdução

A literatura infantil, arte literária produzida para crianças, está presente em nosso país desde a época do Brasil colônia. Porém, esta acompanhou a evolução ocorrida na sociedade. Antes, era mais material para ensinar regras e comportamentos e na atualidade serve como possibilidade de contribuir com a constituição do ser criança ainda em formação. As obras da Literatura Infantil modernas debatem as variadas temáticas numa perspectiva dinâmica, inovadora, questionadora, retratando a criança como ser crítico e ativo.

São muitas as obras atuais que possuem tal característica, entretanto neste trabalho, o objetivo é analisar o livro autobiográfico de Ziraldo, Menina Nina: duas razões para não chorar (2012). Abordaremos a estrutura do texto verbal e não verbal utilizada pelo autor para abordar a temática morte.

Para a composição do escrito recorremos a autores que discutem a importância da Literatura Infantil e sua evolução no decorrer do tempo, tais como Oliveira (2008) e Coelho (2000) já para construir a análise nos embasaremos em Eco (2003), Aguiar (2010), entre outros.

0 artigo divide-se em duas partes. Na primeira será apresentada a importância da Literatura Infantil para o público a qual se destina bem como sua mutação para acompanhar o ritmo da sociedade e na segunda será realizada a análise da obra proposta.

A Transformação Ocorrida na Literatura Infantil desde o seu Surgimento até a Atualidade

Muito se tem discutido nas últimas décadas sobre a importância da Literatura Infantil para a constituição do sujeito e formação de leitores. Porém, a própria definição deste gênero textual é complexa. A grosso modo, pode-se afirmar que a LI é composta de textos escritos para crianças, por isso reúne composições correspondentes ao universo infantil, redigidas com traços poéticos, lúdicos, humorísticos que contribuem para despertar o imaginário dos pequenos leitores.

Oliveira (2018, p. 17) numa tentativa de conceituar esses textos, assim os definiu: 
Literatura infantil é arte! Arte literária produzida para crianças. São textos que supõem 'a criação de sensações ou de estados de espírito, em caráter geral e estético, carregados de vivência íntima e profunda...'. Vivência íntima e profunda da infância, pelo autor, no caso da Literatura Infantil.

Com essa definição, a autora contraria a visão de todos aqueles que subjugam os textos literários produzidos para as crianças e os classificam como gênero menor e pueril, tendo em vista que destaca como característica fundamental dessas obras o seu valor estético capaz de provocar as mais distintas sensações, reflexões e emoções em seus leitores. Esse atributo é imprescindível a todo texto literário.

A Literatura Infantil é capaz de emocionar, ensinar, mesmo que este não seja o seu objetivo principal, proporcionar a descoberta de sentimentos e emoções, tais como a tristeza, a raiva, alegria, entre outros, provocar o imaginário de quem lê ou ouve uma história. E ainda como afirmou Abramovich (2003, p. 17): “[...] é uma possibilidade de descobrir o mundo intenso de conflitos, dos impasses, das soluções, que todos vivemos e atravessamos [...]".

Entretanto, nem sempre a Literatura Infantil (LI) teve esta função, pois em seu início, no Brasil, no século XVIII, ela objetivava prioritariamente ensinar regras e comportamentos.

A educadora e pesquisadora Maria Alexandre Oliveira (2008) constata que não há registros da LI escrita no período de colonização, porém, estes textos, logo nas primeiras décadas já eram divulgados na modalidade oral. A professora relata em seus escritos que por muitos anos, narrativas orais alimentaram o imaginário do público infantil brasileiro, exemplo disso são as histórias de Trancoso, publicados em 1575. Com a vinda da família real para o Brasil, em 1808, houve um avanço significativo para a cultura e a educação. Todavia, apesar de ser material utilizado em salas de aulas nesse período histórico, as obras literárias destinadas ao público infantil “[...] só se justificava para fins didáticos" (OLIVEIRA, 2008, p. 55).

Durante muito tempo, esses textos cumpriram a finalidade de ensinar e moralizar os leitores, contribuíram com a disseminação de valores sociais, normas de boas condutas e regras de uma sociedade ainda em construção (OLIVEIRA, 2008).

Nessa perspectiva, pode-se afirmar que os escritores desses textos não tinham preocupação estética, muito menos necessidade de despertar o imaginário 
das crianças. Esse conceito de se produzir LI vigorou em nosso país até a década de 1920, quando o escritor modernista Monteiro Lobato surge, produzindo textos infantis com características inovadoras (OLIVEIRA, 2008).

Arroyo (1988, p. 83) assim conceitua a LI ocorrida no Brasil desde sua época colonial até início do século XX:

Tais leituras eram quase sempre pesadas, de um espírito moralista acentuando na sua falsidade ou precariedade, obrigacionais, sem o menor interesse pelo entretenimento, como o compreendemos hoje. Seria contra essa literatura desgastada e estéril que Monteiro Lobato iria se voltar no início do século XX.

Com 0 intuito de traçar um comparativo da $\mathrm{LI}$ tradicional com a contemporânea, Coelho (2000) elaborou o quadro a seguir, no qual destaca características bem distintas dessa arte literária.

Quadro 1 - Diferenças entre a LI tradicional e a contemporânea

\begin{tabular}{|c|c|}
\hline O tradicional & O novo \\
\hline Espírito individualista & Espírito solidário \\
\hline $\begin{array}{c}\text { Obediência absoluta à autoridade } \\
\text { valorização do ter e do parecer, } \\
\text { acima do ser }\end{array}$ & $\begin{array}{c}\text { Questionamento da autoridade } \\
\text { do fazer como manifestação autêntica } \\
\text { do ser }\end{array}$ \\
\hline Moral dogmática & Moral da responsabilidade ética \\
\hline Sociedade sexófoba & Sociedade sexófila \\
\hline Reverência pelo passado & Redescoberta e reinvenção do passado. \\
\hline $\begin{array}{c}\text { Concepção de vida fundada na visão } \\
\text { transcendental da condução } \\
\text { humana } \\
\text { cósmica/existencial/mutante da } \\
\text { condição humana }\end{array}$ & Intuicionismo fenomenológico \\
\hline Racionalismo & Anti-racismo \\
\hline Racismo & $\begin{array}{c}\text { A criança ser em formação } \\
\text { ("mutantes"do novo milênio) }\end{array}$ \\
\hline A criança "adulto em miniatura"
\end{tabular}

Fonte: Coelho (2000, p. 19). 
O quadro destaca diferenças importantes entre a LI tradicional e a contemporânea, tendo em vista que toda expressão artística tende a acompanhar a evolução da sociedade e responder aos seus anseios. Observamos que antes alguns personagens infantis presentes nas obras mantinham um espírito individualista, 0 que retrata um indivíduo preocupado apenas consigo, passivo aceitando todas as vontades do adulto, sem questionar e muitas vezes entender, racista, pois retratava a beleza europeia como a única existente.

Com o advento do Modernismo, a reformulação do conceito de criança e a presença de Monteiro Lobato produzindo obras infantis, a LI ganha características artísticas e inovadoras. Isso se intensifica ainda mais a partir da década de 1970. Agora temos personagens que agem como as nossas crianças, ou seja são ativas, questionadoras, demonstram preocupação com o outro, estão sempre ligadas a questões éticas, ambientais e antirracistas. Essas novas características são firmadas nos valores contemporâneos de nossa sociedade: “[...] conhecer a literatura que cada época destinou às suas crianças é conhecer os ideais e valores ou desvalores sobre os quais cada sociedade se fundamentou e fundamenta [...]" (COELHO, 2000, p. 27-28).

$\mathrm{Na}$ atualidade, temos muitas obras com as características citadas acima. Podemos utilizar como exemplo a obra de Ana Maria Machado, História Meio ao contrário, em que a personagem principal questiona a autoridade do pai e se recusa a casar com o príncipe encantado:

\footnotetext{
Meu real pai, peço desculpas. Mas, se o casamento é meu, quem resolve sou eu. Só caso com quem eu quiser e quando quiser. 0 Príncipe é muito simpático, valente, tudo isso. Mas nós nunca conversamos direito. E eu ainda quero conhecer o mundo. Até hoje eu nem sabia que o sol voltava todo dia tão bonito. Tem muita coisa mais que eu quero saber. Isso de ficar a vida inteira fechada num castelo é muito bonito, mas eu vi que aqui fora, nesses campos e nesses bosques, tem muita coisa mais. Não quero me casar agora (MACHADO, 2005, p. 48).
}

Contrariando o estereótipo das princesas tradicionais que sempre anseiam e casam com o tão sonhado principe encantado, a princesa de Ana Maria Machado é dona de seu próprio destino e o tece com suas próprias linhas.

Apesar de Lobato ter inaugurado essa nova estrutra de compor os textos literários infantis, na atualidade temos muitos autores que seguem essa linha e 
escrevem suas obras compondo personagens que respondem às expectativas da criança contemporânea, dentre esses pode-se citar, Ana Maria Machado, Eva Furnari, Ruth Rocha, Tatiana Belinky e Ziraldo.

Neste trabalho, nos dedicaremos a analisar uma obra da LI contemporânea, produzida pelo escritor Ziraldo. Trata-se da obra de arte Menina Nina, duas razões para não chorar.

Menina Nina, Duas Razões para Não Chorar

Menina Nina é uma obra marcante na vida de Ziraldo, pois apresenta um texto autobiográfico que narra a morte de sua esposa Vilma, chamada carinhosamente na obra de vovó Vivi.

Marcelo Marthe, convidado para escrever sobre a obra de Ziraldo, declarou: "Este livro é, sem dúvida, o mais comovente de tantas obras escritas por Ziraldo para crianças." O jornalista não exagerou ao fazer este comentário. Menina Nina é uma poesia do começo ao fim. As palavras, versos, estrofes, ilustrações, arte gráfica foram feitas de tal maneira que é impossível o leitor não se encantar e se emocionar com esta narrativa que trata da própria vida do escritor. o livro, apesar de ser narrativo, foi produzido em versos e estrofes e em muitas passagens é rico em aliterações, o que causa um efeito sonoro importante para a obra: "Vó Vivi vai viver uma nova vida mais nova que a que viveu [...]" (ZIRALDO, 2012, p. 6), "Vovó é uma vocação de avó. Vó Vivi é a vó do ano [...]" (ZIRALDO, 2012, p. 16).

Ziraldo também recorre à figura de construção denominada anáfora, esse recurso contribui para a literariedade do escrito, garantindo ritmo à narrativa e serve para demonstrar como Nina era importante para sua avó Vivi, tanto que ela reparava em cada gesto da menina, desde bebê: "E não quero me gabar, mas estive reparando/no jeito que a Nina tem,/No jeito que a Nina olha,/ no jeito que ela se move [...]" (ZIRALDO, 2012, p. 11).

A obra narra a história da chegada da primeira neta de Ziraldo e Vivi: a menina Nina. Uma obra de arte que nasceu da fusão de duas formas de linguagem: a verbal e não-verbal: 
A conclusão [...] será que sem dúvida a linguagem verbal é o artifício semiótico mais poderoso que o homem conhece; mas que existem, não obstante, outros artifícios capazes de cobrir porções do espaço semântico geral que a língua falada nem sempre consegue tocar [...] Para tornar-se mais poderoso do que é, como de fato ocorre, deve valer-se da ajuda de outros sistemas semióticos (ECO, 2003, p. 154).

Ziraldo soube como aproveitar as imagens nesta composição. 0 que segundo o próprio autor não foi tarefa fácil já que ilustrar esse texto foi para o autor trabalho árduo, como ele mesmo menciona no epílogo de Menina Nina.

A primeira página do livro possui o texto verbal disposto em três estrofes e uma ilustração que ocupa o restante do espaço (uma página e meia). Já neste início é possível depreender a característica de obras contemporâneas que compõem a LI tanto no texto verbal quanto no não verbal. No primeiro, apesar de ser narrativo, é possível perceber a presença de algumas rimas, mesmo que alternadas, como no trecho inicial: "Menina nina amava vó Vivi, que amava sua menina" (ZIRALDO, 2012, p. 4). A ilustração inicial, feita pelo próprio autor, demonstra seu caráter de obra atual, ao não retratar apenas o texto verbal, mas propor um novo texto. A imagem retrata a visão de Nina, ainda no berçário do hospital e consta de várias pessoas, supostamente da família, alguns mais velhos, outros jovens e até crianças, todos felizes e no centro a vovó Vivi sorridente e de braços abertos com a chegada de sua primeira neta.

A imagem foi composta de cores fortes: um fundo azul que contrasta com as cores das roupas dos personagens: branco, vários tons de azuis, vermelho, lilás e verde. É possível também perceber nos traços delicados dos desenhos do autor as distintas emoções sentidas por cada um dos personagens: alegria, entusiasmo, curiosidade. Logo neste início, faz-se necessário o leitor pausar a leitura do texto verbal para atribuir significado ao novo texto composto por cores. Neste momento, em que 0 texto entra em contato com o leitor, várias possibilidades de sentido são construídas a partir da experiência de cada indivíduo. As imagens nesta obra de Ziraldo não servem para meramente traduzir aos pequenos leitores que não sabem ler o significado do texto, mas para agregar outros sentidos ainda maiores ao texto verbal. 
Muitas vezes, o livro de imagens é interpretado pelo adulto como sendo somente para crianças, que ainda não sabem decodificar o texto verbal, quando na verdade esse "objeto novo" oferece várias possibilidades de leituras, em que cada leitor fará a sua, de acordo com as referências culturais e emocionais. Imagem é uma linguagem de conjunto. Estimula múltiplas apreensões, seja pela forma, seja pela cor (OLIVEIRA, 2008, p. 69).

A ilustração é marca importante das obras literárias infantis contemporâneas. Oliveira (2008) nos informa que a primeira obra infantil ilustrada em cores foi 0 patinho feio, publicada em nosso país em 1915. Entretanto, esse texto era tão secundário que nem ao menos o nome do ilustrador era citado na obra. Atualmente, as ilustrações são um texto à parte e possui seu valor estético e literário e tornam-se essenciais para as crianças em processo de aquisição da linguagem escrita:

Ler o texto, interpretar as imagens e interagir com a obra são intensificados pela presença da imagem, que nos permite compreender com Wernek que: a ilustração confere ao livro, além de seu valor estético, 0 apoio, a pausa e o devaneio tão importantes numa leitura criadora (OLIVEIRA, 2008, p. 67).

Esta narrativa é composta de duas partes. Na primeira, um narrador observador, narra uma situação inicial harmônica: a chegada da menina Nina à família e a emoção sentida por vó Vivi. Em uma obra em que duas personagens têm papeis muito importantes, mas a protagonista, como em praticamente todos os textos produzidos por Ziraldo, é a criança. Nos escritos desse autor, a criança possui papel central. E nesta obra não poderia ser diferente: menina Nina é a protagonista.

O narrador passa a relatar as experiências e emoções de se tornar avó. Fica evidente no enredo que vó Vivi é uma mulher determinada, inteligente e viajada: "Vovó Vivi viajava pelo mundo e adorava aeroporto e hotel" (ZIRALDO, 2012, p. 14), mas que com a chegada de sua primeira neta, muitos hábitos são transformados. Agora vó Vivi não vê a hora de voltar para casa e ver o desenvolvimento de Nina.

Ainda nesta primeira parte do enredo, é retratado o envolvimento emocional que Nina tinha com sua avó. O narrador deixa claro que a garota adorava mexer nas caixinhas e fotos antigas da avó. E percebia uma semelhança muito grande entre as duas, fato este que as aproximavam mais ainda, é como se fosse feito uma fusão e transformassem-se em apenas uma: 
A menina aproveitava pra remexer os retratos de todos os bons momentos que vovó Vivi viveu e aí se descobrir nas turminhas do colégio, nos dias de sol na praia, nas viagens pelo mundo, nas datas que não se esquecem e nas comemorações (ZIRALDO, 2012, p. 20).

Neste momento, várias ilustrações distintas são dispostas em duas páginas da obra. Essas mostram Vivi em várias viagens, por locais diferentes do mundo. Trata-se de uma metalinguagem, pois o ilustrador Ziraldo faz o seu retrato ao lado da mulher em quatro imagens diferentes. E Nina aparece, deitada no chão, olhando para um dos álbuns da avó, com jeito de admiração. A narrativa segue sugerindo que Nina se parecia tanto com a avó que chega se confundir em muitas fotos.

A partir dessa página, encerra-se aquele momento inicial da narrativa e surge uma ilustração bem diferente das demais. Enquanto nas outras, os personagens são muito coloridos e aparecem sempre sorrindo, agora, ocupando praticamente duas páginas do livro, surge um fundo azul, com uma janela também azulada, e a Nina em pé de costas, olhando para a lua. Nessa página, a imagem escura e o texto verbal evidenciam que aquela paz inicial chegará ao fim: "E aí teve uma noite em que a Lua lá no Céu cedo se desenhou bem clara e redondinha" (ZIRALDO, 2012, p. 25). Os substantivos "Iua" e "céu" foram grafados em letras maiúsculas revelando um destaque para aquilo está acima de nós: 0 desconhecido. O narrador ainda atribui adjetivos carinhosos para a lua, como se quisesse transformar aquele momento difícil em algo menos doloroso. Pela leitura dessa estrofe podemos inferir que a lua se antecipou para anunciar a tragédia que ocorreria naquela família.

As duas páginas seguintes não possuem ilustrações e narram a angústia de Nina ao acordar e não ter sua avó para tomar o café da manhã juntas, como rotineiramente faziam. Neste momento, o narrador comunica ao leitor o que ocorreu: "Vovó dormia para sempre" (ZIRALDO, 2012, p. 27).

Na página 28, o narrador que até então se utilizava, na maior parte do texto, do discurso indireto, dá voz à personagem que inconsolada com a perda, questiona a avó sobre sua partida prematura e de como será a vida sem aquela presença tão importante: 
Vovó, você nunca disse que queria ir embora assim, sem dizer adeus. Não era isso, vovó, que estava combinado. Vovó, e suas promessas? Vovó, e nossas viagens? Vovó Vivi, e as farras que a gente ia fazer? E a nossa parceria? Vovó, e os meus segredos? Para onde você levou? E como é que eu vou crescer? Sem você me ver crescer? Como vou andar no mundo onde você não está? Vovó, eu não posso mais abraçar as suas pernas, não posso beijar seu rosto, não posso pegar sua mão... Vovó que coisa difícil, Vovó Vivi, que aflição! (ZIRALDO, 2012, p. 28).

Na página seguinte não há texto verbal. A menina Nina aparece em um tamanho maior, com a técnica, contra-plongé ${ }^{3}$, com a mesma roupa com a qual ela olhava a lua na noite anterior, como se estivesse questionando tudo aquilo que estava acontecendo.

A página 30 tem início com uma enorme figura do rosto de Nina chorando. Essa é uma imagem que mexe com a emoção do leitor, pois a morte chega na vida de Nina de uma forma avassaladora. Ziraldo, através de seus traços e cores representa o sofrimento da neta em toda sua essência. Neste momento, o narrador volta para 0 texto, mas não prossegue a narrativa dos acontecimentos. É como se ele precisasse parar o enredo, entrar na história e acalentar o sofrimento daquela menina: "Nina, você vai ter de entender, tem gente que é deste jeito: não gosta de despedidas. Não chore, Nina, não chore. Ou melhor: chore bastante. A gente afoga nas lágrimas a dor que não entendemos" (ZIRALDO, 2012, p. 31).

A página 32 está em branco. Sem texto verbal e nem imagens. As lacunas são comuns em textos literários, pois servem como um momento de respiro para o leitor usar a imaginação, entretanto, dessa vez, Ziraldo deixa um espaço vazado maior que de costume para que o leitor desenvolva sua imaginação e sentimentos. A página seguinte não traz imagens, e inicia com a conjunção adversativa MAS, destacada em negrito e caixa alta, informando ao leitor que uma ideia contrária à exposta na página anterior virá: "MAS espere, Nina, espere, porque há duas razões para você não chorar" (ZIRALDO, 2012, p. 33). Neste momento, percebemos que narrador se arrepende do conselho dado anteriormente e pede que a menina pare de chorar. Talvez tenha feito isso por perceber que o sofrimento era grande e que ela não estava sabendo lidar com a perda.

\footnotetext{
${ }^{3}$ Termo em francês que remete a captação de um indivíduo ou objeto de cima para baixo, em toda a sua dimensão.
} 
Na página 34, Nina aparece dormindo em sua cama, sonhando com sua avó. O sonho representa épocas diferentes. No primeiro, as duas andam de mãos dadas, sorrindo. Neste sonho, Nina ainda é uma criança. Já no sonho seguinte, as duas aparecem de costas, abraçadas e Nina já está crescida. A imagem de Nina dormindo e sonhando é de paz e tranquilidade. 0 texto verbal disposto na outra página inicia com a conjunção condicional SE, também destacada em negrito e caixa alta. Neste momento, o narrador emite uma condição para a menina não chorar:

Se muito além desse sono que vovó está dormindo não existe nada mais como muita gente crê - não existe despertar, nem porto destino ou luz; se tudo acabou de vez - acabou, completamente - pode ter certeza, Nina, a vovó está em paz; não sabe nem saberá que está dormindo para sempre (ZIRALDO, 2012, p. 35).

A penúltima página inicia com um desenho que ocupa mais de uma página do livro, com Nina em pé em sua cama, olhando para o auto e acenando, como se quisesse chamar a atenção de alguém, que pelo enredo compreendemos ser da avó. $O$ texto verbal final também inicia com a conjunção condicional $S E$, mas neste momento o narrador oferece outra possibilidade à menina: "SE, porém, depois desse sono intenso Vovó Vivi despertar num outro mundo, feito de luz e de estrelas, veja, Nina, que barato!!! Que lindo virar um anjo. Que lindo voar no espaço" (ZIRALDO, 2012, p. 37).

Lendo o mundo, Ziraldo torna possível a correlação entre o mundo simbólico e 0 mundo real por meio dos processos analógicos, primeiramente, e, mais profundamente, pragmático-discursivos, integrando, nos livros, palavra e imagem: é uma simbiose criativa, que desperta o prazer estético, graças à singularidade e à plurissignificação dos traços, das cores, da palavra, da fantasia concretizada (FERES, 2011, p. 46).

O narrador não volta a narrar os acontecimentos na vida de Nina e encerra a obra, com essas duas possibilidades de encarar a morte, em ambas não há razão para chorar. Como Ziraldo está narrando um fato verdadeiro de sua vida, é como se ele tivesse que abandonar o papel que desempenha tão bem, o de narrar acontecimentos, para cuidar, aconselhar, sarar as feridas deixadas em sua neta, pela partida repentina de sua avó. É como se o autor deixasse sua própria dor de lado para cuidar da dor do outro. Ele deixa de ser o escritor Ziraldo e passa a ser 0 avô Ziraldo, o avô da menina Nina. 
Essa literatura infantil - acima de tudo, literatura; infantil, pelo processamento - é uma das artes de Ziraldo; arte na expressão e na escolha temática; na poeticidade. Temas universais, abordagens cheias de imaginação, sentidos exigentes de interpretação e de emoção (FERES, 2011, p. 48).

Muitas outras obras infantis abordam a temática morte dos avós em seus enredos, porém este escrito de Ziraldo se mostra diferente em muitos pontos destes outros títulos para crianças, tendo em vista que, apesar de não mencionar a idade de Vivi dentro do texto verbal, as ilustrações mostram uma mulher de meia idade, contrariando o estereótipo de avós, Vivi não possui os cabelos completamente brancos, presos em coques e nem passa os dias fazendo crochês ou cozinhando para a neta. Ziraldo apresenta a ilustração de mulher jovial, elegante, inteligente, apaixonada por viagens, aeroportos e hotéis. 0 texto verbal também descreve vovó Vivi dessa forma: "Vovó Vivi era linda, se casou tão bonitinha, tinha sido a vida inteira, bonita como uma artista de cinema de seu tempo" (ZIRALDO, 2012, p. 18).

A pesquisadora Paiva (2008) ao realizar uma pesquisa que constou da análise de 1735 obras infantis que fazem parte do Programa Nacional da Biblioteca Escolar (PNBE) constatou que apenas $3 \%$ abordavam a temática morte.

Ao realizarmos uma primeira leitura dos doze títulos que tratam da morte é possível constatar que, por trás de todas as histórias narradas, há uma única e grande história, a do pequeno ser humano em contacto com a finitude da vida. Entretanto, constatamos, também, que metade deles se refere à morte de avós, indicando, de certa maneira, uma tendência de se privilegiar uma morte "natural", já que são velhos e chegou a hora, mas, em geral, conseguem se despedir e deixar boas lembranças e ensinamentos para os pequenos que ficam (PAIVA, 2008, p. 47).

Em Menina Nina, a neta não consegue se despedir da avó, pois pelo que nos é informando pelas duas linguagens presentes na obra, tudo estava transcorrendo perfeitamente bem, quando em uma manhã, Vó Vivi não apareceu para o café da manhã. Pela leitura não é possível saber a causa da morte, porém em pesquisas à biografia do autor, tomamos conhecimento que assim ele narra, pois busca aproximação com a realidade dos fatos, já que Vivi faleceu de infarto enquanto dormia: "Nina você vai ter de entender, tem gente que é deste jeito: não gosta de despedidas" (ZIRALDO, 2012, p. 31). 
Aguiar (2010) entende que a morte dentro dos contos da Literatura Infantil serve ora como punição de algum personagem mau, como é o caso do lobo mau em vários contos tradicionais, ora como possibilidade de apresentar à criança leitora a informação de que após a morte de um ente querido há uma reconfiguração da estrutura familiar, gerando complicações e exigências de soluções. Este último parece ser a ideia do escritor Ziraldo, pois ele encerra a narrativa com a estrofe composta de dois versos com a constatação: "Dos dois jeitos desse adeus/é a gente que inventa a vida" (ZIRALDO, 2012, p. 37). Essa é uma lição que Nina aprendeu com sua avó, conforme é relatado na página 22 “E reaprendia então, uma lição da vovó: viver é inventar a vida". Esse ensinamento agora serve para a menina compreender que é possível continuar sendo feliz, e é ela quem deve inventar a sua vida e suas crenças sobre o que acontece após o falecimento de um ente querido.

Podemos afirmar que esta obra de Ziraldo possui todas as características estéticas necessárias as obras da LI contemporânea, por ser produzida em linguagem literária que permite múltiplas interpretações, mexe com os distintos sentimentos inerentes ao ser humano.

Neste livro, Ziraldo de forma majestosa encontra na poesia uma maneira para tratar de um tema tão sombrio e doloroso para todos: a morte. Utilizando de eufemismos como: "[...] vovó está dormindo para sempre", "ela está sonhando, Nina" "Que lindo virar um anjo" "Vovó, você nunca disse que queria ir embora, vovó dormia serena como viveu, vovó dormia para sempre", ele não deixa de mostrar que a morte ainda é um mistério, até mesmo para os adultos. 0 narrador de menina Nina não sabe o que de fato aconteceu com vó Vivi após sua morte, mas sabe que de uma forma ou de outra que Nina resolver acreditar, será um modo de inventar a vida.

A poeticidade também pode ser observada nas metáforas utilizadas para definir a palavra avó: "Vovó Vira mãe/multiplicada por duas" (ZIRALDO, 2012, p. 6), "vovó é uma matriosca" (ZIRALDO, 2012, p. 8). 0 escritor recorre a relações semânticas da língua na tentativa de conceituar a importância da palavra avó. 
Considerações Finais

A Literatura Infantil, desde a época do Brasil colônia, desempenha um papel importante, apesar de distinto dos dias atuais, na vida das crianças leitoras. Antes, com 0 intuito de doutrinar, moralizar e na atualidade tem o fito de divertir, propor reflexão, despertar a imaginação, tudo pelo viés lúdico, poético e artístico.

As obras atuais representam crianças ativas, críticas, questionadoras, vivenciando problemas comuns aos pequenos, como a descoberta, o maravilhoso, 0 medo, tristeza, alegria, perdas. Dentre tantos autores contemporâneos que criam personagens que povoam o imaginário infantil, um que se destaca por excelência tanto na linguagem verbal quanto não verbal é Ziraldo.

Autor de muitas obras conhecidas no Brasil, Ziraldo revolucionou sua própria escrita ao produzir a obra autobiográfica Menina Nina, duas razões para não chorar. De uma forma poética, recorrendo a figuras de linguagens, tais como: eufemismo e aliteração, o escritor aborda um tema tão complexo até mesmo para os adultos: a morte. Ao relatar, o sentimento de perda de sua primeira Neta Nina, ao inesperadamente receber a notícia de que sua avó Vivi faleceu, o autor cria imagens poéticas, tanto por meio da linguagem verbal quanto não verbal, mas não idealiza esse momento, pelo contrário, insere a personagem Nina dentro de um contexto de decisão e possibilidades. Será ela quem irá decidir o que de fato ocorreu com sua avó após a morte.

Em um misto poético de texto verbal, Ziraldo recorre às ilustrações de forma encantadora. Em sua obra, elas não ocupam lugar de legenda, mas contribuem para ampliar o sentido do texto.

Assim é Menina Nina, uma obra encantadora, instigante, literária, poética e acalentadora que contribui para que leitores de diferentes idades se identifiquem com a protagonista na perda de um ente querido; ademais a vivência literária cria afetamentos, contribuindo para humanizar leitores, bem como fomenta novos interesses e desejos pelo ato de ler a produção estético-literária materializada nos livros. 


\section{Referências}

ABRAMOVICH, Fanny. Literatura infantil: gostosuras e bobices. 5. ed. São Paulo:

Scipione, 2003.

AGUIAR, Vera Teixeira de. A morte na literatura: da tradição ao mundo infantil. In: AGUIAR, Vera Teixeira de; CECCANTINI, J oão Luís; MARTHA, Alice Áurea Penteado (Org.). Heróis contra a parede: estudos de literatura infantil e juvenil. São Paulo: Cultura Acadêmica, 2010. p. 23-42.

ARROYO, Leonardo. Literatura infantil brasileira. São Paulo: Melhoramentos, 1988.

COELHO, Nelly Novaes. Literatura infantil: teoria, análise e didática. 7. ed. São Paulo: Moderna, 2000.

ECO, Umberto. Tratado geral de semiótica. 4. ed. São Paulo: Perspectiva, 2003.

FERES, Beatriz dos Santos. A semiose poética em Ziraldo. In: GARCÍA, Flávio; MICHELLI, Regina; PINTO, Marcello (Org.). 0 insólito e a literatura ju venil. Rio de J aneiro: Dialogarts, 2011. Disponível em:

www.dialogarts.uerj.br/arquivos/livro_pronto_comunicacoes_livres.pdf. Acesso em: 27 out. 2017. p. 42-54.

MACHADO, Ana Maria. História meio ao contrário. 25. ed. São Paulo: Ática, 2005.

OLIVEIRA, Maria Alexandra. A literatura para crianças e jovens no Brasil de ontem e de hoje: caminhos de ensino. São Paulo: Paulinas, 2008.

PAIVA, Aparecida. A produção literária para crianças: onipresença e ausência de temáticas. In: PAIVA, Aparecida; SOARES, Magda (Org.). Literatura infantil: políticas e concepções. Belo Horizonte: Autêntica, 2008. p. 35-52.

ZIRALDO. Menina Nina: duas razões para não chorar. 2. ed. São Paulo: Melhoramentos, 2012. 